\title{
The learning curve revisited. A study in four companies
}

\author{
B.O. Rorsted \\ Dept. of Management, University of Aarhus \\ University Park 350, DK-8000 Arhus C, Denmark \\ Phone: +4589421 570, Fax: +4586135132 \\ E-mail: broersted@econ.au.dk
}

\begin{abstract}
This paper reports briefly on the analyses of recent productivity development data carried out in four different companies with the expectation that learning/experience effects might be identified in different company settings. It may be recalled that the learning curve expresses that direct labor costs of an item or type of activity decrease at a constant percentage as the accumulated number of repetitions keeps doubling. Since organisational back-up would appear to facilitate faster learning, an experience component is often considered additional to the pure learning component, but separation of the two may prove difficult.

The two first companies offered uncomplicated examples of personal or small group learning with focus, first, on machine-assisted pile-driving, and second, on getting acquainted with a new offset printing press. The two last companies offered quite complicated examples of big group and organisational learning with focus, third, on the mounting of large package sorting systems by several teams working in parallel waves, and fourth, on aspects of learning how to build a new type of ship by a shipyard.
\end{abstract}

Keywords

Coordination, group learning, learning rate, planning, project complexity.

\section{TWO SIMPLE GROUP TASKS}

In the first study a group of five experienced men assisted by a mobile pile driver began driving piles along an existing railway line as a preparation for electrification. 791 piles were driven over 31 nights at an over-all learning rate of 
$95.0 \%$, which is the slightly surprising but conventional way of expressing that costs are being reduced by $5.0 \%$ at each doubling of the accumulated number of repetitions. Learning during the first three nights and $1 / 8$ of the piles, however, was as high as $68.9 \%$, and learning over the last 28 nights was as low as $97.2 \%$.

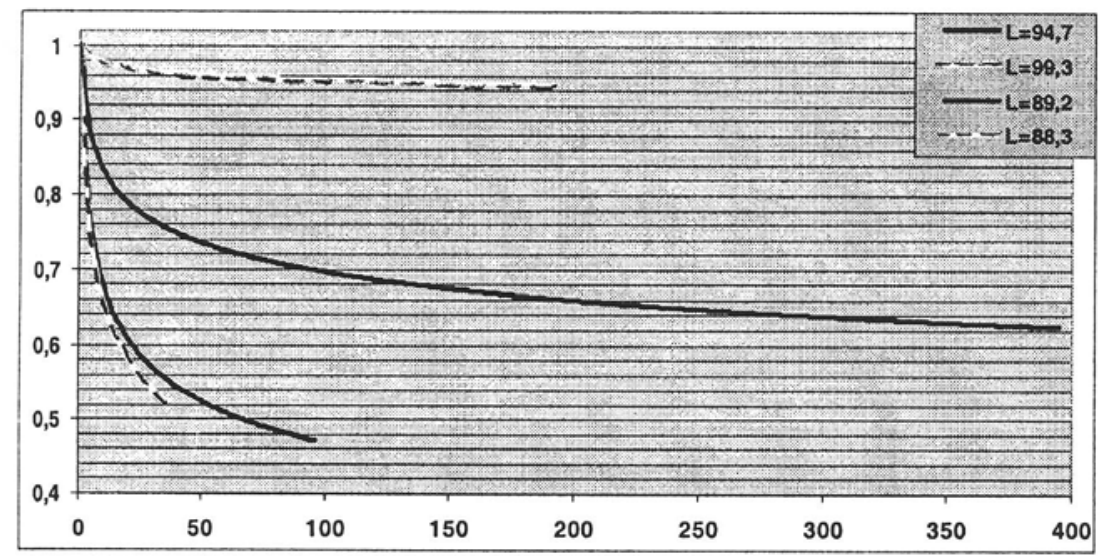

Figure 1 Learning curves for all, first half, first fourth and first tenth of 393 setups.

In the second study an offset printing company had acquired a new eight station printing machine with special features and high complexity. The running-in by existing staff was recorded over the first 18 weeks and 93 orders comprising 393 set-ups, and again over-all learning rate was a moderate $94.7 \%$ while learning in the first $10 \%$ fractile was higher, at $88.3 \%$. This result was compatible with company wisdom: It takes a couple of weeks to master the special features of a new press and after three months the press may be operated as any other press.

In both cases it appears that skilled people, alone or in small groups, at tasks within their range of skills may adapt quickly to what little new there may be in a new man-machine situation.

Learning curve diagrams could of course be traced as illustrated in Figure 1, which for the second study shows learning rates for the total of 393 press set-ups as well as for the first half, the first quarter and first tenth. Learning rates increase as the first fractile is decreasing in size. The low learning rate of the first half of this particular set of data reveals that the chosen analytical method is quite sensitive to that observation which divides neighbouring fractiles. The over-all picture remains clear, however. 
The third study addressed group learning with regard to mounting 33 large package sorting systems. All components had been manufactured so that the mounting operation was solely man-paced and the learning rate, according to learning curve literature, might therefore be as high as $70 \%$. Over-all learning did in fact reach $73.7 \%$. Of special interest, however, was the fact that information was available for each system in terms of hours spent on 26 different items, and that numbers of mounted units were available where applicable. In-depth analysis was thus feasible and a more detailed project description seems justified.

The total project comprised the mounting and running-in of 33 similar but not identical sorting systems on 33 different geographical locations far from company home. Eight mounting teams would in four waves accomplish their tasks with maximum self-sufficiency since contact with home base would cost time and money once the teams were on location. Consequently, the entire project involving some 60 man-years was prepared like a military operation for maximum productivity.

Eight designate team leaders would as a first group mount a pilot sorting system, developing methods, seeking best solutions, and considering their joint experiences. Each group member would then lead this own team of seven additional members, four of whom were freshly recruited and three were company employees familiar with sorting systems in general; and each team would mount a sequence of four individual systems.

The total scheme, consequently, offered the opportunity to analyse three types of learning in addition to the over-all learning rate of $73.7 \%$ mentioned above. First of all, the ability of the team leaders to transfer what they had learnt from mounting the pilot system to their own eight teams mounting their first wave systems. Secondly, the over-all ability of the teams to learn from their first wave systems to their last wave systems, and thirdly, the learning of each individual team from its first to its last system. Thanks to the detailed data available for 28 of the systems the three analyses mentioned could be applied to each of six different types of components as well as to total variable hours per 100 metres of system length.

Of the 26 items for which hours were recorded, six reflected the different numbers of six major components of a sorting system, while five items reflected the different lengths of the sorting systems. Overall learning in these direct variable hours was $72.0 \%$. Eight items reflected various tasks associated with lay-out and running-in of the sorting systems. Over-all learning in these direct fixed hours was $73.7 \%$. The last seven items reflected various tasks which were insensitive to the dimensions of a sorting system, such as receiving and marking materials, preparing the site and coordinating the work. Over-all learning in these indirect hours was a mere $83.3 \%$, consistent with a rather limited opportunity of developing adeptness in this kind of work. 


\section{Transfer of experience to teams}

As mentioned above, the entire operation started with eight designate team leaders mounting a pilot sorting system, thus developing first hand experience and hopefully qualifying for the leader responsibility. While not strictly learning, it is interesting to observe that the ability of the team leaders to transfer their experience - combined with the ability of team members to absorb this wisdom varies with the complexity of mounting different types of component. Carts, of which an average sorting system required app. 2500, were mounted at a ten percent better productivity in the first wave than at the pilot system, while code readers, of which there were app. 350 in an average system, required $43 \%$ more hours than in the pilot system. The transfer

of knowledge of how best to mount code readers, apparently, was not easy.

Table 1 Over-all team learning - index and rate „L“ - by component

\begin{tabular}{|c|c|c|c|c|c|c|c|c|}
\hline \multicolumn{2}{|r|}{ Components } & \multicolumn{6}{|c|}{ Direct Hours (Index per Wave) } & \multirow[b]{2}{*}{$L$} \\
\hline Units & Type & 0 & 1 & 2 & 3 & 4 & 5 & \\
\hline 9435 & Code Readers & 100 & 143 & 117 & 97 & 75 & 56 & 69.7 \\
\hline 2246 & Motors & 100 & 136 & 84 & 73 & 58 & 55 & 68.3 \\
\hline 7008 & Multi-S & 100 & 107 & 63 & 43 & 36 & 43 & 67.9 \\
\hline 11030 & Shifting Devices & 100 & 91 & 98 & 78 & 57 & 57 & 80.0 \\
\hline 74926 & Carts & 100 & 90 & 76 & 63 & 50 & 45 & 74.5 \\
\hline 224 & Cross Fields & 100 & 72 & 53 & 46 & 35 & 37 & 73.3 \\
\hline 55828 & Frame Mounting (m) & 100 & 77 & 60 & 54 & 51 & 45 & 80.7 \\
\hline
\end{tabular}

\section{Over-all team learning}

For several reasons the original scheme of four waves was modified for the later sorting systems so that eventually five waves were formed, No detailed information is available to indicate exactly how work was distributed over the members of each team, or what each individual person contributed to the joint performance. For each team and for each wave, however, data on hours spent on the mounting of each type of component as well as on mounting the system framework are available.

Information on over-all team learning is shown in Table 1, which firstly, lists the six types of component and the system framework as well as the number of units of each for the entire 28 systems; and secondly, in index form the development in hours spent per component from the pilot system - wave zero - to wave five. The index numbers in the wave one column, in particular, show the over-all effect of transfer of team leader experience to team members reported in the previous section. The far right column, finally, shows overall team learning by component calculated from the index numbers spanning wave one to wave five. On the plausible assumption that all team members mounted their equal shares of all components, learning ranged between a high of $67.9 \%$ for multi-suspensions to a low of $80.0 \%$ for shifting devices. In the light of the results from the study of the two first simple tasks, where the very early learning appeared to be faster than 
learning over the longer stretch, we should perhaps note that the first observations of time per component are registered at different distances from the starting points as a reflection of the numbers used per system. The wave one index thus refers to the first 64 cross fields but also to the first 21500 carts. This weakness, however, cannot be remedied.

One could speculate, of course, that the development of manual dexterity which must be a major element of the personal learning process, may not necessarily be component-specific but might be of a more general nature within the limited variety of component types used in sorting systems.

On the assumption that for mounting purposes a component is a component, regardless of type, a common learning curve could be derived from regarding all observations as a homogeneous set of data. A such curve would entail well over 12 redoublings, since $2^{11}=2048$ while the average number of all components over all team members was 2358 . The learning rate would be $72.6 \%$.

Table 2 Individual team learning rates by component

Team (Observations)

\begin{tabular}{lrrrrrrr} 
Components & Interval & $1(3)$ & $3(4)$ & $5(4)$ & $4(4)$ & $6(4)$ & $8(4)$ \\
\hline Code Readers & $31-210$ & 71.3 & 80.3 & 54.0 & 68.2 & 83.2 & 74.3 \\
Motors & $9-51$ & 102.1 & 82.0 & 67.5 & 64.0 & 65.3 & 92.3 \\
Multi-Suspensions & $25-169$ & 89.9 & 53.2 & 64.1 & 69.0 & 58.2 & 73.8 \\
Shifting Devices & $40-260$ & 63.4 & 80.3 & 99.8 & 81.3 & 84.0 & 77.4 \\
Carts & $301-1715$ & 80.1 & 72.9 & 68.9 & 80.1 & 72.9 & 79.5 \\
Components above & $411-2401$ & 81.0 & 75.0 & 78.0 & 73.9 & 71.3 & 79.6 \\
Cross Fields & $1-5$ & 73.2 & 80.1 & 78.0 & 71.8 & 68.1 & 67.9 \\
Frame Mounting & $208-1280$ & 83.7 & 82.5 & 79.6 & 82.3 & 77.5 & 75.9 \\
\hline
\end{tabular}

\section{Individual team learning}

While part of the learning observed in the individual teams must originate in the dexterity of the team members, another part is likely to reflect the particular manner of operation which developed among the team members with regard to division of work, sequence of tasks, mutual assistance, planning, and coordination etc.

The last major analysis aimed at tracing the learning of each team over its sequence of mounting sorting systems. Since minor exchanges of team members between teams and a few staff adjustments took place, this analysis follows the individual team leaders.

Table 2 shows a total of eight learning rates for each of the six teams which completed at least three projects. At this level of detail the analysis becomes increasingly sensitive to inaccuracies of the data, so that the most reliable results are "components above" and ,frame mounting" which still show some scatter and thus reflect team individuality. Further break-down, however, is infeasible. 


\section{Effect of coordination}

One item among the indirect hours reported pertained to coordination as an unspecified activity, presumably performed mostly by the team leaders and reflecting their style of leadership, interacting both with the team and with cooperating organisations in the environment, for example the constructor of the building in which a sorting system was being mounted. On the hypothesis that more time spent on coordination would tend to reduce the number of system direct hours, a correlation analysis was conducted which resulted in a coefficient of correlation of -0.092 , which as expected, is at least negative.

\section{A COMPLICATED COMPANY TASK}

For the fourth study a huge amount and diversity of data was available about the productivity development in building a series of seven "new“ ships by 2000 employees at a Danish shipyard. Discussion may thus be more promising than analysis. Assuming that a ship is a ship and that shipyards might enjoy a learning rate of $80 \%$, hours spent on these seven ships, numbered no. $731-737$, thus located half way between no. 512 and no. 1024, could be expected to decline by a mere $0.27 \%$ from no. 731 to no. 737 , which no empirical analysis could reveal.

With few exceptions, however, such as the Liberty-ships during World War two, ships tend to be more unique than identical, and so OECD has defined a method by which a number of different factors may be applied in order to reduce ship uniqueness, including size, to a common measure, „Compensated Gross Tonnes“ (CGT), which, as one would suspect, cannot fully account for all ship differences. There remains, then, an element of newness whenever a shipyard accepts an order for a series of ships, and this affords the opportunity to begin a new learning curve which exploits the so-called sistership-effect. For shipyard operations it is vital to estimate accurately the hours required for the first ship and the learning rate by which the hours for the subsequent ships in the series will decline. If total hours for the series are underestimated, congestion will occur, deliveries may be delayed and economy suffer. If total hours are overestimated, capacity utilization will drop and economy may also suffer. Successive revisions of current estimates may be desirable.

\section{Estimating first ship hours and learning rate}

Information on hours required to build nine moderately different ships in Danish shipyards displayed a scatter of total hours per CGT between 22 and 35. The scatter reflects a combination of ship differences not accounted for in CGT and yard differences in productivity, construction principles, technology and building method. Estimating first ship hours for a particular ship and yard, obviously, must be based on specific projection. 
Learning rates for different recent series of ships were on record. The lowest rate $91.7 \%$ - was found in one series of six ships and the highest - $81.7 \%$ - in another of four. Learning rates from a different yard showed $90.5 \%$ over six, $86.6 \%$ over ten, and $85.6 \%$ over 17 ships. No clear conclusion is indicated by these data. Assuming rational behavior, increasing number of ships in one series would prompt more careful preparation, including up-front development of new fixtures and methods. This would reduce total building hours and possibly reduce first ship hours at the expense of less learning potential and thus a lower learning rate.

Management of this yard regarded the seven ships as a - relatively - long series. First ship hours were cautiously estimated at 32 per CGT, in the upper part of the previously mentioned interval of 22 to 35 , and the sistership-effect was cautiously estimated at $92.4 \%$, slightly lower than the until now lowest rate in the $91.7 \%$ to $81.7 \%$ interval, previously mentioned. The corresponding learning curve is shown as curve $\mathrm{A}$ in Figure 2.

\section{Half-way corrections}

Six months into the building of the first ship and with ship no. 2 well underway, management assessed the building performance and found it necessary to adjust total first ship hours from index 100 to index 130.

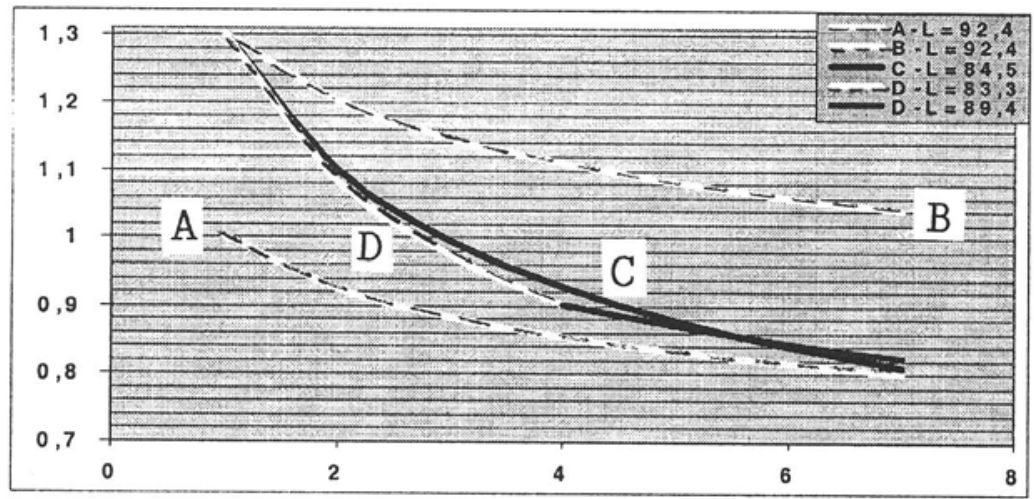

Figure 2 Four successive estimates of first ship hours, index, and learning rate.

At the initially estimated learning rate of $92.4 \%$, total hours for the series would have been 611 or an average of 87 per ship. At unchanged learning the increase of first ship hours would raise the series' total to index 794 or 113 per ship, curve B, but management merely raised total hours by $11 \%$ to index 672 or 96 per ship, apparently expecting that almost $2 / 3$ of the increase in first ship hours could be compensated for by an increase in the sistership-effect from $92.4 \%$ to $84.5 \%$, curve C. In addition, earlier learning was foreseen with a rate for ships no. 1-4 of $83.3 \%$ slowing to a rate of $89.4 \%$ for ships no. 4-7, curve D in Figure 2. 
As ship no. 1 approached completion, actual hours spent were increasingly replacing estimates, and continuous upward adjustments were required as the net effect of many deviations. How should the learning rate be changed in order to compensate for these overruns? Could a greater learning potential become available and would the yard have the necessary learning ability?

At this stage management believed that the learning potential was unchanged in spite of overruns and that increased learning on the later ships would compensate for the overruns on ships no. 1 and 2. Consequently, the halfway learning rate of $84.5 \%$ was increased to an over-all rate of $68.6 \%$, composed of an accelerated $65.1 \%$ for ships no. $1-4$ and a slower $77.9 \%$ for ships no. $4-7$ as illustrated by curve A in Figure 3. These estimates should later prove quite optimistic.

There were, in fact, two reasons for the overrun in first ship hours. On one hand, a number of things went wrong such as delays in subsupplies and faulty specifications which caused rework. Such overruns must be eliminated by preventive action but are no platform for learning. On the other, several low hour estimates were replaced by higher actual hours, and these may be reduced by learning.

Assuming a 50-50\% spilt of the two, the halfway estimate of index 130 first ship hours should then for learning purposes be reduced to index 115 , shown as curve B.

A comparison with the originally estimated learning curve A in Figure 2, shown again as curve $\mathrm{C}$ in Figure 3 illustrates that the yard now expected to build ships no. 3-7 at fewer hours than initially estimated in spite of all first ship overruns. This halfway assessment should later prove too optimistic and turned out to be merely the first of a long sequence of upward adjustments of hours needed and downward adjustments of the learning rate feasible. The target of eventually completing this series of seven ships was constantly moving as more and more hours were put into the building proces which may actually bring the shipyard into bankrupcy.

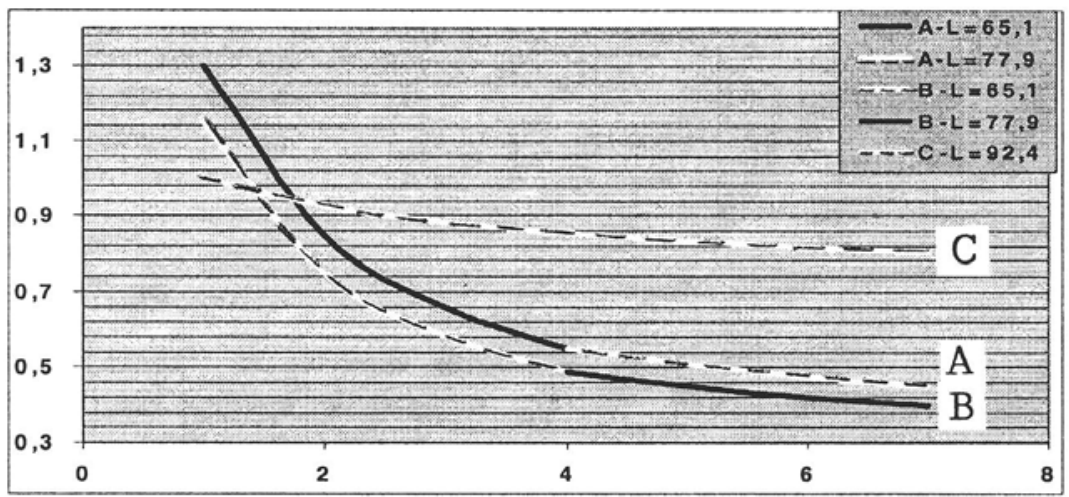

Figure 3 Final estimates of first ship hours, index, and learning rate. 


\section{CONCLUSIONS}

The four studies would appear to represent the full range of learning. The piledriving and running-in of a new printing press suggest that individuals are quick in adapting to a moderately new task within their range of skills. A learning rate may be clearly identified through the first few repetitions but as the accumulated number of repetitions keeps redoupling it becomes increasingly difficult to isolate a learning rate from the noise in the available data, and newness may have worn out.

The study of mounting 33 package sorting systems is a striking example of how careful preparation may facilitate learning in small groups who face a moderately complicated new task comprising great numbers of repetition of small operations. The shipbuilding study, however, illustrates that newness of a very complicated project may exceed the capability of a large organisation and that learning ability may be insufficient to exploit the learning potential over only few repetitions.

\section{BIOGRAPHY}

Bendt O. Rorsted received his degree from the University of Aarhus and after several years as a business consultant and lecturer was appointed professor of managerial economics at the Department of Management in 1970. With a Harvard ITP background he continues consulting and post-graduate education. $\mathrm{He}$ is a director of several companies and an academic expert to the TEMPUS program of the European Economic Commission. Operations management is among his interests. 